\title{
Wireless Telemetry for Electronic Pill Technology
}

\author{
Mehmet R. Yuce, Tharaka Dissanayake, Ho Chee Keong \\ School of Electrical Engineering and Computer Science, The University of Newcastle, \\ University Drive, NSW 2308, Australia.mehmet.yuce@newcastle.edu.au
}

\begin{abstract}
This work will address the challenges to facilitate the development of a high capacity radio system for a small, miniaturized electronic pill device that can be swallowable or implantable in human body in order to detect biological signals or capture images that could eventually be used for diagnostic and therapeutic purposes. In addition to reviewing and discussing the recent attempts in electronic pill technology, a wideband (UWB) telemetry system aimed for the development of an electronic pill will be presented in this paper. We have successfully realized more than half a meter UWB link under conditions emulating an implant
\end{abstract}

\section{INTRODUCTION}

Recent development in electronic pill technology requires the integration of more complex systems on the same platform when compared to conventional implantable systems. A small miniaturized electronic pill can reach areas such as small intestine and deliver real time video images wirelessly to an external console. Fig. 1 shows a wireless endoscope (i.e. electronic pill) for a medical monitoring system. The device travels through the digestive system to collect image data and transfers them to a nearby computer for display with a distance 1 meter or more. A high resolution video based capsule endoscope produces a large amount of data, which should be delivered over a high capacity wireless link.

Since its early development [1]-[3], wireless endoscope (i.e. electronic pill) designs have been based on narrow band transmission and thus have limited number of camera pixels. One of current state-of-the-art technologies for wireless endoscope device is commercially available by the company "Given Imaging" [4]. The pill uses the Zarlink's RF chip [5] for wireless transmission based on the Medical Implant Communication Service (MICS) band. The allowable channel bandwidth for this band is only $300 \mathrm{kHz}$. It is difficult to assign enough data rate for the high quality video data at the moment for a real time monitoring. It is quite obvious that there is a need for higher-bandwidth data transmission for electronic pills that could facilitate a better diagnosis.

Wideband technology- (UWB communication) is an ideal physical layer solution that achieves a data rate equal or higher than $100 \mathrm{Mbps}$. Its current applications are mostly for in-door entertainment, radar and imaging. Due to high losses in body tissue at high frequencies many are skeptical about using UWB for implanted and, moreover, ingested devices. This challenge can only be addressed by combined design of antennas, transmitters and receivers as described in this paper. In addition to reviewing and discussing the recent attempts in

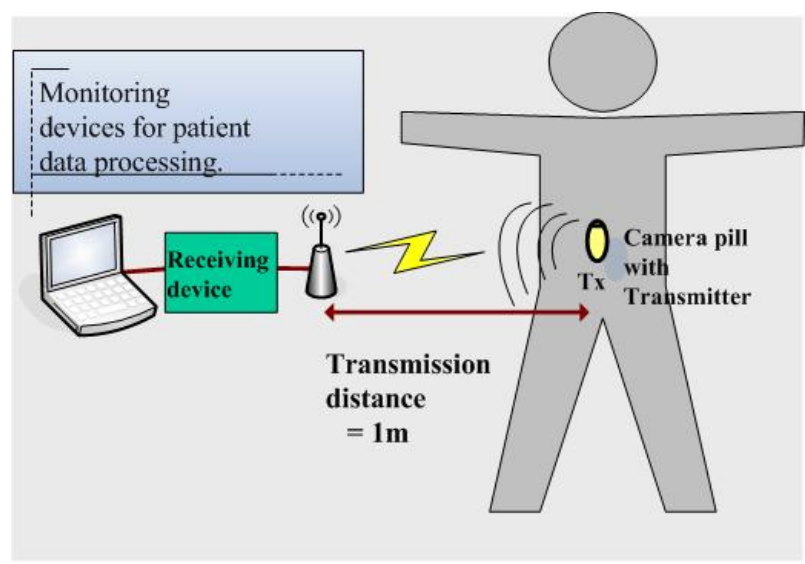

Fig. 1. A wireless endoscope monitoring system.

electronic pill technology, a wideband telemetry system aimed for the development of an electronic pill will be presented in this paper. We have successfully realized more than half a meter UWB link under conditions emulating an implant

\section{WiRELESS TELEMETRIES USED IN ELETRONIC PILL}

There are plenty of publications describing the current trend on wireless endoscopes and technologies. One of the recent articles given in [7] gives a good history of capsules from their early development to clinical implementation. The design of wireless capsules started around 1950s. Since then, they have been called as endoradiosondes, capsule, smartpill, electronic pill, wireless capsule, wireless endoscopy, video capsule and so forth. Herein we will use the term electronic pill to cover all these names. The early attempts were based on low frequencies and with simple structures [1][6]. A basic transmitter using Collpitts or Hartley oscillator topology connected to a sensor has been used to send the signal from inside the body to external devices for tracking physiological parameters of inner organs. Despite simplicity, the early systems were bulky due to large electronic components and batteries used and were targeting temperature, $\mathrm{pH}$ and pressure [8][9].

As the electronic device should deeply be placed inside the body, which makes the wireless communication interesting due to its surrounding medium, the recent attempts in electronic pills have also been limited to low frequency transmissions (UHF-433 ISM or lower) [10]-[16]. The low

M. R. Yuce and Ho Chee Keong ' work is supported by the Australian Research Council (ARC) under Discovery Projects DP0772929. 
TABLE II. RECENT RESEARCH PROJECT OUTCOMES ON ELECTRONIC PILL.

\begin{tabular}{|c|c|c|c|c|c|c|c|c|c|}
\hline Reference & $\begin{array}{l}\text { Image } \\
\text { Resolution }\end{array}$ & $\begin{array}{l}\text { Image } \\
\text { sensor }\end{array}$ & Frequen. & $\begin{array}{l}\text { Data } \\
\text { Rate }\end{array}$ & $\begin{array}{l}\text { Modu- } \\
\text { lation }\end{array}$ & $\begin{array}{l}\text { Trans. } \\
\text { Power }\end{array}$ & $\begin{array}{l}\text { Physical } \\
\text { Dimension }\end{array}$ & $\begin{array}{l}\text { Power } \\
\text { Supply }\end{array}$ & $\begin{array}{l}\text { Current } \\
\text { Power }\end{array}$ \\
\hline $\begin{array}{l}\text { (Thone, } \\
\text { 2009)[14] }\end{array}$ & $\begin{array}{l}640 \times 480 \\
\text { pixels }\end{array}$ & $\begin{array}{c}\text { MT9V013 } \\
\text { (VGA) }\end{array}$ & $144 \mathrm{MHz}$ & $2 \mathrm{Mbps}$ & FSK & $-18 \mathrm{dBm}$ & Not finalized & $\begin{array}{c}3 \mathrm{~V} \\
\text { coin cell } \\
\end{array}$ & $\begin{array}{c}\text { NA } \\
(2 \mathrm{~mW} \text { for } \\
\text { Tx })\end{array}$ \\
\hline $\begin{array}{c}\text { (Chen, 2009) } \\
{[10]}\end{array}$ & $\begin{array}{c}307,200 \\
\text { pixels }\end{array}$ & $\begin{array}{l}\text { VGA, } \\
0-2 \text { fps }\end{array}$ & $433 \mathrm{MHz}$ & $\begin{array}{l}267 \\
\text { kbps }\end{array}$ & FSK & NA & $\begin{array}{c}11.3 \mathrm{X} 26.7 \\
\mathrm{mmxmm}\end{array}$ & $\begin{array}{c}2 \mathrm{X} 1.5 \mathrm{~V} \\
\text { silver- } \\
\text { oxide }\end{array}$ & $\begin{array}{c}8 \mathrm{~mA}(24 \\
\mathrm{mW})\end{array}$ \\
\hline $\begin{array}{l}\text { (Wang, } \\
\text { 2008) [13] }\end{array}$ & $\begin{array}{c}510 X 480 \\
\text { pixels }\end{array}$ & $\begin{array}{c}\text { PO1200 } \\
\text { CMOS }\end{array}$ & NA & NA & $\mathrm{AM}$ & $\begin{array}{c}\text { High } \\
\text { (variable) }\end{array}$ & $\begin{array}{c}10 \times 190 \\
\text { mmxmm }\end{array}$ & $\begin{array}{c}3 \mathrm{~V}, \\
\text { wireless }\end{array}$ & $125 \mathrm{~mW}$ \\
\hline $\begin{array}{c}\text { (Kfouri, } \\
2007)[16]\end{array}$ & $\begin{array}{c}768 \times 494 \\
\text { pixels }\end{array}$ & $\begin{array}{c}\text { CCD } \\
\text { ICX228AL }\end{array}$ & UHF & $\begin{array}{c}250 \\
\mathrm{kbps}\end{array}$ & -- & NA & $\begin{array}{l}20 X 100 \\
m m x m m\end{array}$ & $\begin{array}{l}\text { Li-ion } \\
\text { battery }\end{array}$ & -- \\
\hline $\begin{array}{c}\text { Park, 2002) } \\
{[13]}\end{array}$ & $\begin{array}{c}510 X 492 \\
\text { pixels }\end{array}$ & $\begin{array}{l}\text { OV7910 } \\
\text { CMOS }\end{array}$ & $315 \mathrm{MHZ}$ & NA & $\mathrm{AM}$ & NA & $\begin{array}{c}10 \times 7 \\
\mathrm{mmxmm}\end{array}$ & $5 \mathrm{~V}$ & NA \\
\hline $\begin{array}{l}\text { Johannessen, } \\
\text { 2006) [11] }\end{array}$ & $\mathrm{pH}$ and Temp. & $\begin{array}{l}\text { Sensory: } \mathrm{pH} \\
\text { and Temp. }\end{array}$ & $433 \mathrm{MHz}$ & $4 \mathrm{kbps}$ & OOK & $\mathrm{NA}, 1 \mathrm{~m}$ & $\begin{array}{c}12 \mathrm{X} 36 \\
\mathrm{~mm}, 8 \mathrm{~g}\end{array}$ & $\begin{array}{c}\text { 2X1.5 V } \\
\text { SR48 } \\
\text { Ag2O }\end{array}$ & $15.5 \mathrm{~mW}$ \\
\hline $\begin{array}{l}\text { Valdastri, } \\
2004 \text { [12] }\end{array}$ & Multi-channel & Sensors & $433 \mathrm{MHz}$ & $13 \mathrm{kbps}$ & ASK & $\begin{array}{c}5.6 \mathrm{~mW} \\
5 \mathrm{~m}\end{array}$ & $\begin{array}{c}27 \mathrm{X} 19 \mathrm{X} 19 \\
\mathrm{~mm}^{3}\end{array}$ & $\begin{array}{c}3-\mathrm{V} \\
\text { coin cell } \\
\text { (CR1025) }\end{array}$ & -- \\
\hline $\begin{array}{l}\text { Mackay, } \\
1957[1]\end{array}$ & $\begin{array}{c}\text { pH, temp., } \\
\text { oxygen level }\end{array}$ & Sensors & $100 \mathrm{kHz}$ & -- & FM & -- & -- & -- & -- \\
\hline
\end{tabular}

The highlighted section is for visual based electronic pill systems.

frequency transmission is easy to design and is found attractive due to its high efficiency. However a low frequency link requires large electronic components such as capacitors and inductors, which makes it difficult to realize a complete integrated system.

After recent significant technology improvements, design of small size camera and battery could have been possible. Thus in the last ten years some research projects looking at developing electronic pills have concentrated mostly on the visual sensor system. Thus a high frequency link is required for better resolution and a miniaturized system. Recent telemetry systems being developed for the electronic pill technology are summarized in Table I. All these systems are still at prototype levels.

In [10], a wireless endoscope system uses a commercial RF transceiver operating at $433 \mathrm{MHZ}$ ISM with $267 \mathrm{kbps}$. The electronic pill includes a passive wireless link used for wake-up to reduce power consumption. The wake-up system recovers energy from a $915 \mathrm{MHz}$ RF modulated signal with some sort of identification code. This capsule does image compressing techniques using an ASIC to enable higher transmission rate of images for low-data rate systems.

The pill in [11] uses a simple OOK wireless system. Similar to the early developments, this device transfers the physiological data- $\mathrm{pH}$ and temperature. Another such device was developed by Valdastri, et al., in [12] with a multichannel feature to cover few different physiological parameters. It was tested in vivo in pigs using pressure sensors. The transmission range was reported as $5 \mathrm{~m}$. These devices do not require high data rate comparing to the video based electronic pills highlighted in Table I because physiological parameters like $\mathrm{pH}$ and temperature are lowfrequency signals. Simple modulation schemes like On-Off Keying (OOK) and Amplitude Shift Keying (ASK) with low- data rate are desired for the purpose of low-power consumption and miniaturization.

Another type of capsule is the robotic endoscope [13] which additionally has features such as locomotion and the energy transmission using electromagnetic coupling. Although the device size is quite large comparing to other proposed systems, it is probably because of these additional functionalities. Similar to smartpill, such a device can be used for precise drug delivery in the human gastrointestinal tract. Real-time energy transfer is necessary for these types of endoscopes to provide mechanical function as they require large power for continuous movement.

A recent study [14] demonstrated a prototyping system to achieve high data rate $(2 \mathrm{Mbps})$ for higher image resolution. It can enable an image resolution up-to 15-20 fps (frame per second) using compression technique like JPEG. It uses a simple Colpitts oscillator. The transmitter itself thus consumes low-power. However the actual power consumption of a device could only be realistic when all blocks of an electronic pill are integrated together. The device operates at $144 \mathrm{MHz}$, relatively lower than most of the systems that are operating at UHF, which necessitates a larger antenna that will increase the physical size. In [15], Park, et al. also uses a simple AM (amplitude modulation). It is designed with a mixer and an oscillator circuit together with the CMOS image sensor and a loop antenna to form a capsule-shaped telemetry device. This device uses an external control unit to control the capsule inside the human body.

Another category of electronic pill technology is to use fluorescence spectroscopy and imaging, similar to those that are commercially available. Kfouri, et al., studied a fluorescence-based electronic pill system that uses UV light with illumination LEDs to obtain clearer images [16]. This is like flash based digital camera widely used by people. Due to 
the use of power hungry LEDS, such a device consumes power higher than the other available systems. An alternative power source together with battery is required to support the electronics continuously. A wireless power, from outside to inside, has been suggested. Although not specified, it probably used UHF frequency as the RF transmission.

From Table I, it seems that in current attempts the transmission frequency has been limited to around UHF frequencies. Although the advances in high frequency and high bandwidth communication technologies for wireless systems have been significant in the commercial domain, these technologies are not directly transferable to biomedical implant or ingested systems due to the differing power, size, and safety related radiation requirements. As an example, in [17] an implant prototyped with a ZigBee compliance -one of the low-power, less complex and small size commercially available wireless standard occupies an area of 26X14X7 mm without being integrated with other required blocks of an electronic pill. The existing advanced wireless systems such as ZigBee (IEEE 802.15.4), WLANs, and Bluetooth (IEEE 802.15.1) operate at $2.4 \mathrm{GHz}$ ISM band and suffer from the strong interference from each other when located in the same environment [18]. Thus an electronic pill should probably have a different transmission band for an interference free wireless system. The existing wireless modules contain complex multi-access communication protocols such as OFDMA that increase the power consumption and size of the wireless chip. Unless these chips are miniaturized to levels that can be inserted into a capsule size of $11 \mathrm{mmX} 30 \mathrm{~mm}$, the telemetry used will still be based on simple communication modulations like ASK, OOK, FSK, AM.

Table II summarizes the commercially available electronic pill technologies that are already been used in clinical environments. Current wireless endoscope device by "Given Imaging" is used to diagnose disorders such as Crohn's disease, Celiac disease, benign and cancerous tumors, ulcerative colitis, gastrointestinal reflux disease (GERD), and Barrett's esophagus [4]. The pill uses the Zarlink's RF chip for wireless transmission [5]. The chip uses the MICS band that allows channels with only $300 \mathrm{kHz}$. It is thus difficult to assign enough data rate for the high quality image and video data at the moment for a real time data transfer and monitoring.

RF Norika by RF system lab has a wireless power capability and localization capabilities. Another endoscope EndoCapsule was developed by Olympus was mainly used in Europe. However in 2007 it has received marketing clearance from the Food and Drug Administration (FDA). The device contains 6 LEDs with adjustable illumination to maintain optimal imaging. Currently all the video based commercial systems being designed are based on illumination. The electronic pill by SmartPill is designed to measure pressure, $\mathrm{pH}$ and temperature as it passes through the GI tract. A receiving device worn by the patient collects data which is later examined by a physician. With information obtained from public domain, these pills are described in Table II.

Due to the limited transmission bandwidth used for the electronic pills that are currently being developed or the ones commercially available, the image transfer rate has been limited to 0-10 frames per second. As high definition cameras are continuously being developed, they will be attractive for use in electronic pill. However, a higher pixel camera will require higher image transfer rate. As an example, if $1920 \mathrm{x}$ 1080 pixel (2 megapixel) charge-coupled device (CCD) sensors to be integrated in an electronic pill, it will require a data rate of $33.2 \mathrm{Mbit} /$ frame, considering 2 Bytes are used per frame. Currently such a high data rate is not possible with any of the available telemetry systems in electronic pills. If the allowable bandwidth used with UHF frequencies, transmission of this data rate will only give a transmission time of 10 s or more per frame which will result in very small motion for a video streaming. Although compression techniques could be used to some extend, it reduces the image equality. Thus in future, a dedicated frequency band with larger bandwidth is required for high definition image transmission.

Since miniaturization is important, different design approaches have been followed by the designers. Fig. 2 illustrates different shapes that has been used or can be used to integrate all the necessary blocks. As shown, each unit can be designed on a separate board layer and then stacked on top of each other. In a design shown in Fig. 2-(a) antenna can be placed such that it can easily be inserted on top of the transmitter layer. The capsule shape is also divided into two regions where antenna can be designed to be placed in upperhalf whereas the remaining electronic units are packed in the lower-half. Placing electronic units on one side of antenna is another possibility (Fig. 2-(c)). Commercially available mini cameras can easily be integrated with electronic pills [19]. Small miniature rechargeable battery technologies are also being developed [20] with a dimension around $5 \mathrm{~mm}$ and can easily be integrated in a capsule structure shown in Fig. 2.

TABLE II. COMPARISON OF HARDWARE DESIGNS FROM VENDORS, www.givenimaging.com, http://www.olympus-europa.com/endoscopy/, www.rfsystemlab.com, www.smartpillcorp.com.

\begin{tabular}{|c|c|c|c|c|c|c|c|}
\hline Model & Company & $\begin{array}{l}\text { Camera } \\
\text { (Sensor) }\end{array}$ & $\begin{array}{l}\text { Freq. } \\
\text { (MHz) }\end{array}$ & $\begin{array}{l}\text { Data } \\
\text { Rate }\end{array}$ & $\begin{array}{l}\text { Power } \\
\text { Source }\end{array}$ & $\begin{array}{l}\text { Physical } \\
\text { Dimension }\end{array}$ & $\begin{array}{l}\text { Image rate and } \\
\text { resolution }\end{array}$ \\
\hline PillCam (SB) & $\begin{array}{l}\text { Given } \\
\text { Imaging }\end{array}$ & Micron, CMOS & $\begin{array}{c}402-405 \\
\& 433 \\
\text { (Zarlink) } \\
\end{array}$ & $\begin{array}{c}800 \\
\text { kbps } \\
\text { (FSK) }\end{array}$ & Battery & $\begin{array}{c}11 \mathrm{X} 26 \\
\operatorname{mmxmm},<4 \mathrm{gr}\end{array}$ & $\begin{array}{c}14 \text { images per } \\
\text { second, or } 2,600 \\
\text { color images }\end{array}$ \\
\hline EndoCapsule & $\begin{array}{l}\text { Olympus } \\
\text { Optical }\end{array}$ & $\begin{array}{l}\text { CCD camera, } \\
1920 \times 1080\end{array}$ & -- & -- & Battery & $\begin{array}{c}11 \mathrm{X} 26 \\
\mathrm{mmxmm}\end{array}$ & $\begin{array}{l}2 \text { images per } \\
\text { second }\end{array}$ \\
\hline Norika & $\begin{array}{c}\text { RF System } \\
\text { Lab }\end{array}$ & $\begin{array}{c}\text { CCD Image } \\
\text { sensor }\end{array}$ & -- & -- & $\begin{array}{c}\text { Wireless } \\
\text { Power }\end{array}$ & $\begin{array}{c}9 \mathrm{X} 23 \\
\mathrm{mmxmm}\end{array}$ & NA \\
\hline SmartPill & $\begin{array}{l}\text { Smartpill } \\
\text { Corp. }\end{array}$ & $\begin{array}{l}\text { acidity }(\mathrm{pH}), \\
\text { press., temp. }\end{array}$ & -- & -- & Battery & $\begin{array}{c}13 \mathrm{X} 26 \\
\mathrm{mmxmm}\end{array}$ & $\begin{array}{l}\text { Only sensor } \\
\text { discrete data }\end{array}$ \\
\hline
\end{tabular}




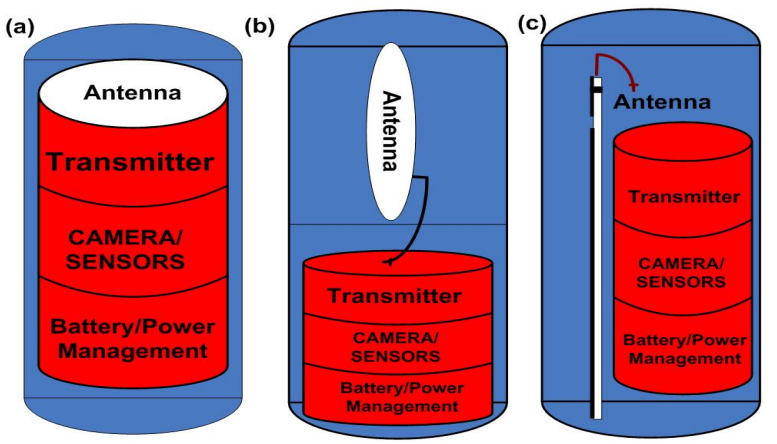

Fig. 2. Possible physical shapes for electronic pills

\section{IW-UWB TELEMETRY FOR ELECTRONIC PILL}

Although the image based electronic pill systems listed in Table I \& II can provide some level of accuracy, for some diseases detailed images may be required [21]. Thus a better resolution camera will be used. In order to monitor high quality images in real-time, a wideband radio link will be desired for a high capacity data transfer and thus improved image resolution [14][22]. A wideband, high frequency technology will especially be useful for high definition images exceeding 2 megapixels (i.e. $>1920$ x 1080). Although there have been ongoing advancements in UWB communication for short range applications; they cannot directly be applied to electronic pill technology because of different design and optimizations required due to stringent physical constraints and biological safety. In the following section, we will study the feasibility of wideband technology for electronic pills.

The important parameters of the wideband technology are its low power transmitter design, low-interference effect in medical environment and high data rate capability. The design of a UWB wireless chip has been difficult for chip designers due to the difficulty in the demodulation of narrow pulses with a low signal power level. Generally a UWB receiver circuit has demonstrated power consumption higher than that of a narrow band system. One way to eliminate the high power consumption of an ultra wideband transceiver is to use a transmitter only in the electronic pill that will not need a signal from external unit to the electronic pill in the body.

The use of wideband technology for medical implants should overcome unique challenges associated with the high frequency implementation. To address these challenges, as preliminary work in this study, we present a complete working UWB prototype with a capsule-shaped antenna specifically designed for the targeted application. The selected band is $3.5-4.5 \mathrm{GHz}$ (i.e. band-limited), which avoids narrowband systems operating in the ISM bands. The initial design has been tested in a laboratory environment demonstrating that an impulse-based UWB system is an attractive design for wireless endoscope monitoring. The result shows that with UWB signals it is possible to transmit data at a rate of $100 \mathrm{Mbps}$.

The prototype system used in the experiment is shown in Fig. 3, with transmitter and receiver waveforms shown explicitly. A low-cost, printed, capsule-shaped UWB antenna has been designed for the targeted application [23]. The printed antenna presented herein demonstrates good matching in the frequency band of $3.5-4.5 \mathrm{GHz}$ and the radiation performance has been evaluated experimentally using the IUWB transmitter/receiver prototype to show that it is suitable for an electronic pill. The antenna matching has been optimized using CST Microwave Studio, commercial electromagnetic simulation software. Proposed antenna is printed on a $0.5 \mathrm{~mm}$ thick RO4003 capsule-shaped, low loss, dielectric substrate $\left(\varepsilon_{r}=3.38\right)$. It can easily fit inside a size-13 capsule. Overall length and width of the antenna is $28.7 \mathrm{~mm}$ and $14 \mathrm{~mm}$, respectively. The antenna has been optimized using simulations and printed on one side of the substrate together with a Grounded-CPW (Coplanar Wave Guide) feed as shown in Fig. 4.

Several transmitters have been designed to generate UWB signals. Short pulses are mainly generated according to the OOK and Pulse Position Modulation (PPM) modulated signal. At the transmitter, the pulse generator unit produces a rectangular- shaped pulse with 1 ns width (Fig. 3-(a)). The spectrum of the rectangular pulse extends over an unlimited frequency band. Thus a Band Pass Filter (BPF) centered at 4 $\mathrm{GHz}$ with $1 \mathrm{GHz}$ bandwidth is used to constrain the signal power under the Federal Communications Commission (FCC) emission mask (i.e. a band limited UWB system). The energy of the side lobes is maximized within the bandwidth of the bandpass filter. The filtered pulses are fed into our custom made UWB antennas, shown in Fig. 3 and 4.

The receiver can easily be designed for a high data rate as it is built from off-the-shelf high performance RF components by using high performance RF ICs (i.e. Amplifiers, Mixers) and high speed Field Programmable Gate Arrays (FPGA). There are different receiver architectures that can easily be constructed. Usually a mixer is used to down convert the high frequencies to low frequencies. Herein a diode is used due to simplification in the successive blocks. The received UWB signal is passed through a BPF, whose center frequency is 4 $\mathrm{GHz}$, to eliminate possible interference from the frequencies of WLAN standards (for example $2.4 \mathrm{GHz}$ and $5 \mathrm{GHz}$ ). The signal is then amplified by the Low Noise Amplifier (LNA). A diode and a Low Pass Filter (LPF) down converts the UWB signal and the baseband data is finally recovered by the FGPA. At the receiver end, the main component is the diode detector. When small input signals below $-20 \mathrm{dBm}$ are applied to the diode, it translates the high frequency components to their equivalent low frequency counterparts due to its nonlinear characteristic. Measurement results, shown in Fig. 3(b) are spectrum plots at the outputs of the receive antenna and the low-noise amplifiers.

UWB prototype is capable of supporting a low-power UWB communication, which will be ultimately used to form an in-body-to-air link, without violating FCC regulations. Antennas were placed inside a plastic container. Prior to each measurement, jacket of aluminum foil covered the outer surface of the container to minimize outside coupling paths between the antennas.

First measurement was taken inside the empty container and the second with a meat sample inside. Measured S21 using the VNA is shown in Fig. 5. Coupling between antennas in the same laboratory environment and instrument calibration 

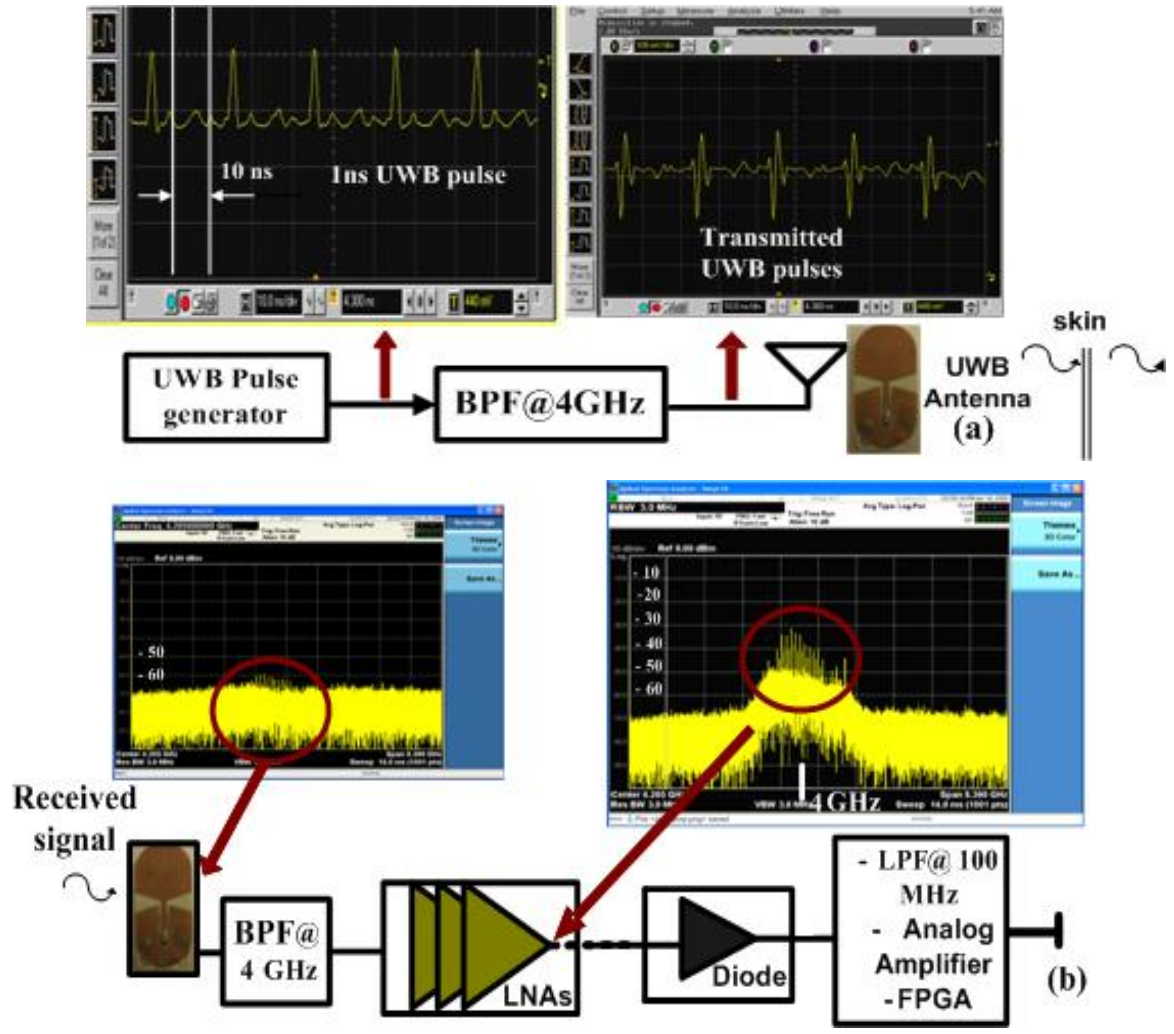

Fig. 3. A ultra wideband (UWB) wireless telemetry prototype and measurement results,(a) transmitter with 1 ns UWB pulse, and (b) receiver with spectrums.

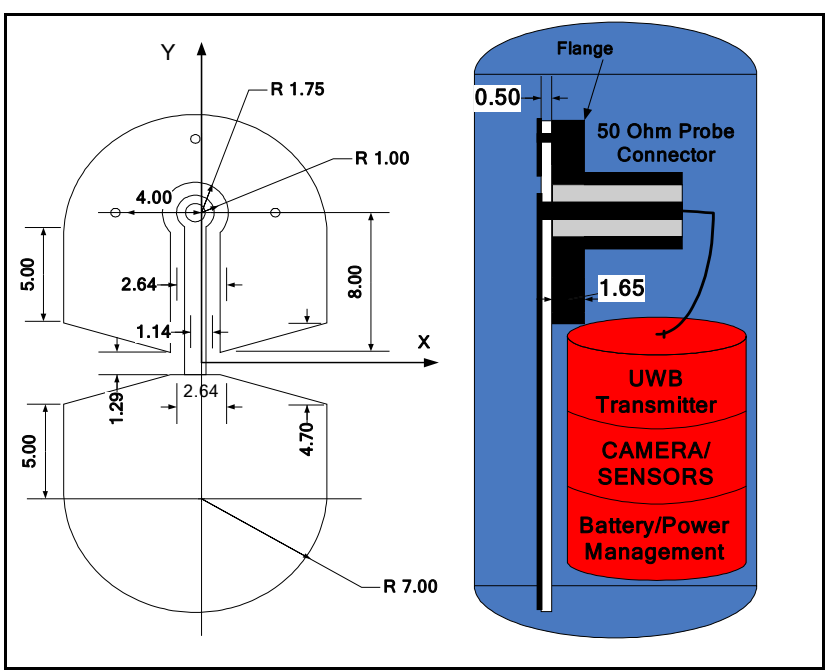

Fig.4 . A wireless electronic pill system with antenna dimensions.

for both through the meat and free space, are shown for comparison. There is about $20-30 \mathrm{~dB}$ attenuation through meat within $3-5 \mathrm{GHz}$ band for every $2 \mathrm{~cm}$. This attenuation is not only due to absorption by meat but also due to the antenna mismatch due to presence of meat also contributes to this. Furthermore, high gain antennas systems with large aperture can be used at the receiver unlike the one in the miniature pill. Subsequently, the overall gain of the system will be improved to counter the attenuation by tissue.

For a UWB transmitter, the regulation requires the signal output to be $-41 \mathrm{dBm} / \mathrm{Hz}$ or lower. To make UWB transmission feasible for electronic pills, we propose to use higher transmitted signal levels at the transmitter. The UWB signal power is arranged such that when the signal is radiated through the skin, the power level should meet the FCC mask. Considering the strong attenuation through the body tissue, the transmitter power level will be adjusted from $-20 \mathrm{dBm}$ to 20 $\mathrm{dBm}$ in our system, without violating safety requirements.

Unlike the other designs, in our approach, the implanted device does not contain a receiver. The transmission is one directional as the information needs to be recorded and monitored only. This simplifies the complexity of the device and increases its battery lifetime. When more than one electronic pill is used in the same environment, an individual device ID (PN code) will be used in the transmitted signal to eliminate interference between two devices or other UWB devices [24]. As we only need a transmitter design for the implanted system, the transmitter power consumption and complexity will be traded off with that of the receiver as the receiver is located outside and its power consumption and size are not crucial.

Receiver circuits implement power hungry analog blocks like LNA and mixers at the front-ends. Using only a UWB transmitter, analog blocks of commerical transceivers are avoided in our electronic pill approach, which not only increases the battery life but also reduces the physical size. Using this approach a UWB telemetry link has been tested over a $0.6 \mathrm{~m}$ across the laboratory both in free-space and when loaded with meat emulating an implant once a high gain antenna is used at the receiver site instead of one shown in Fig. 4. Using a high gain antenna at the receiver we could 
reduce the tissue effect by $20 \mathrm{~dB}$ and more [23]. The $50 \mathrm{MHz}$ data stream is obtained at the FPGA after the demodulation process. The time domain signals before and after the FPGA are shown in Fig 6. The recovered signal is a $50 \mathrm{Mbps}$ pulse obtained from UWB pulses with width of $1 \mathrm{~ns}$.

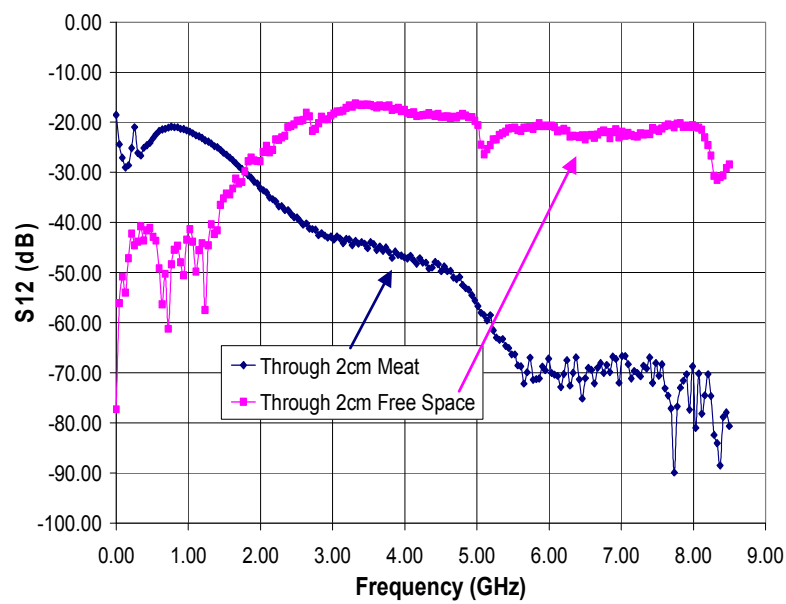

Fig. 5. UWB transmission through meat (s21 measurement).

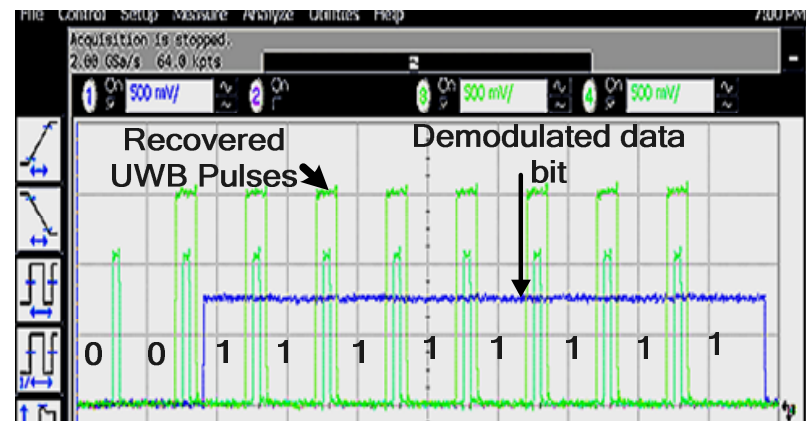

Fig.6. Received and demodulated UWB signals.

\section{CONCLUSION}

A high capacity radio system is currently necessary for electronic pill technology in order to visually examine the digestive tract wirelessly with better and detailed images. Techniques and methodologies have been presented in this paper for the use of wideband technology in a miniaturized electronic pill to provide a high capacity wireless channel. A prototyping system including UWB transmitter/receiver and antennas has been developed to investigate the feasibility of a high data rata transmission for the electronic pill technology. Integration of antenna with the UWB transmitter electronics has been considered in a capsule shaped structure. Although it is known that tissue imposes strong attenuation at higher frequencies, we have shown there are some advantages to use wideband technology.

Due to the high data rate capacity (e.g. $100 \mathrm{Mbps}$ ), a wideband electronic pill can transmit raw video data without any compressing, resulting low-power, less delay in real-time and increased picture resolution. With a high definition camera such as 2 megapixels, UWB telemetry can send up to 10 frame per second (fps). We believe that the wideband pill technology is going to open up a new set of diagnostic systems for medical professionals to analyze real-time video and image data wirelessly as a less invasive method.

\section{REFERENCES}

[1] R. S. Mackay," Endpradiossonde," Nature vol. 179, 1957

[2] G. Meron, "The development of the swallowable video capsule (M2A)," Gastrointestinal Endoscopy, vol. 6, pp. 817-8199, 2000.

[3] M. Q. H. Meng, et al., "Wireless Robotic Capsule Endoscopy: State-ofthe Art and Challenges," in the 5th World Congress on intelligent Control and Automation, 2004, vol. 6, pp. 5561-5565.

[4] http://www.givenimaging.com//, 2009.

[5] P. Bradley, "An ultra low power, high performance medical implant communication system (MICS) transceiver for implantable devices," in the IEEE Biomed. Circuits and Systems Conference, pp. 158-16, 2006.

[6] J. Nagumo et al., " Echo capsule for medical use," IRE Transaction on Bio-medical Electronics, vol. 9., pp. 195-199, 1962.

[7] C. Mc Caffrey, et al. "Swallowable-capsule technology," Pervasive computing, January-March, 2008.

[8] V. K. Zworykin, "Radio pill," Nature, vol. 179, p. 898, 1957.

[9] R. S. Mackay and B. Jacobson, "Radio telemetering from within the human body," Science, vol. 134, pp. 1196-1202, 1961.

[10] X. Chen et al. "A wireless capsule endoscope system with low-power controlling and processing ASIC," IEEE Transation on Biomedical Circuits and Systems, Vol. 3, February 2009.

[11] E. A. Johannessen, et al. "Biocompatibility of a lab-on-a-pill sensor in artificial gastrointestinal environments," IEEE Trans. Biomed. Eng., vol. 53, pp. 2333, Nov. 2006.

[12] P. Valdastri, A. Menciassi , A. Arena , C. Caccamo and P. Dario "An implantable telemetry platform system for in vivo monitoring of physiological parameters," IEEE Trans. Inform. Technol. Biomed., vol. 8, pp. 271, Sep. 2004.

[13] K. Wang, G. Yan, P. Jiang, and D. Ye, “ A wireless robotic endoscope for Gastrointestine," IEEE Trans. Robotics, Vol.24, pp. 206-210, February 2008.

[14] J. Thone, S. Radiom, D. Turgis, R. Carta, G. Gielen, and R. Puers, "Design of a 2 Mbps FSK near-field transmitter for wireless capsule endoscopy," Sensors and Actuators A: Physical, 2008.

[15] H. J. Park, et al., "Design of bi-directional and multi-channel miniaturized telemetry module for wireless endoscopy," in Proc. 2nd Int. IEEE-EMBS Conf. Microtechnologies in Medicine and Biology, 2002, pp. 273-276.

[16] M. Kfouri, et al., "Toward a miniaturised wireless fluorescence-based diagnostic imaging system," IEEE J. Selected Topics in Quantum Electronics, vol. 14, Jan/Feb, 2008.

[17] P. Valdastri, A. Menciassi, P. Dario, "Transmission power requirements for novel ZigBee implants in the Gastrointestinal tract," IEEE Trans. Biomedical Engineering, Vol.55, June 2008.

[18] S. Y. Shin, H. S. Park, and W. H. Kwon, "Mutual interference analysis of IEEE 802.15.4 and IEEE 802.11b," Computer Networks, vol. 51, August 2007, Pages 3338-3353.

[19] VD6725,STMicroelectronics, http://www.st.com/stonline/products/literature/bd/14370.pdf, 2009.

[20] Smallbattery. 2009. http://www.smallbattery.company.org.uk/hearing_aid batteries.htm.

[21] S. L. Jungles, "Wireless capsule endoscopy a diagnostic tool for early Crohn's Disease," US Gastroenterology Review 2005 - April 2005.

[22] C. Kim, T. Lehmann, S. Nooshabadi and I. Nervat, "An ultra-wideband transceiver architecture for wireless endoscopes," International Symp. Commun. and Information Tech., pp. 1252-1257, 2007.

[23] T. Dissanayake, M. R. Yuce and Ho C. K. "Design and evaluation of a compact antenna for implant-to-air UWB communication," IEEE Antennas and Wireless Prop. Letters, vol. 8, Page(s):153 - 156, 2009.

[24] N. Aydin, T. Arslan, and D. R. S. Cumming, "Design and implementation of a spread spectrum based communication system for an ingestible capsule," IEEE Trans. Information Technology in Biomedicine, Vol.9, March 2005. 